\title{
Definition of Zones With Different Levels of Productivity Within an Agricultural Field Using Fuzzy Modeling
}

\author{
Dmitry Kurtener ${ }^{1}$, H. Allen Torbert ${ }^{2}$, Viktor Yakushev $^{1}$ \& Elena Krueger ${ }^{1}$ \\ ${ }^{1}$ Agrophysical Research Institute, St. Petersburg, Russia \\ ${ }^{2}$ USDA-ARS National Soil Dynamics Laboratory, 411 S. Donahue Dr. Auburn, AL 36832, USA \\ Correspondence: Dmitry Kurtener, Agrophysical Research Institute, Grazhdansky pr. 14, 195220 St. Petersburg, \\ Russia. Tel: 7-812-534-1324. E-mail: dmitrykurtener@hotmail.com
}

Received: December 27, 2012 Accepted: March 20, 2013 Online Published: April 15, 2013

doi:10.5539/jas.v5n5p176

URL: http://dx.doi.org/10.5539/jas.v5n5p176

\begin{abstract}
Zoning of agricultural fields is an important task for utilization of precision farming technology. A method based on fuzzy indicator model theory for definition of zones with different levels of productivity is considered. Fuzzy indicator model for identification of zones with different levels of productivity is based on two general types of fuzzy indicators: the individual fuzzy indicator (IFI) type and the combined fuzzy indicator (CFI) type. IFIs are defined as a number in the range from 0 to 1 , which reflect an expert concept and are modeled by an appropriate membership function. CFI is defined using fuzzy aggregated operations. The theoretical considerations are illustrated with this example based on data collected from a precision agriculture study in central Texas, USA. Soil samples were collected at different points, taking into account the actual longitude and latitude for each of these points. Because the experimental data (as in many cases) contained information only about a limited number of parameters, the calculations were restricted in this study. In this study, the parameters grain yield, total carbon $(\mathrm{C})$, total nitrogen $(\mathrm{N})$, and available phosphorus $(\mathrm{P})$ were utilized. Using the author's computer program, fuzzy indicators IFI/CFI was calculated for each zone separately. Utilizing results of calculations maps of zones with different levels of productivity were built.
\end{abstract}

Keywords: fuzzy set theory, fuzzy indicator, zoning of agricultural fields, precision farming

\section{Introduction}

Within-field variability is a well-known phenomenon in agriculture and is central to the precision farming concept. One way of dealing with this problem is to subdivide a field into a few contiguous homogenous zones, often referred to as management zones (MZs) (Handbook of precision agriculture-principles and applications, 2006). However, decisions must be made as to how these management zones will be delineated. The evaluation of MZs delineation is the subject of many scientific research studies.

The delineation of management zones could be based on factors such as soil and field characteristics (Fridgen, 2000; Fridgen et al., 2004), digital elevation model (Pilesjo et al., 2000) and yield maps (Stafford et al., 1999). Another method is based on the use of GIS software. Yield values are calculated on a cell-by-cell basis and a map of average yield values is created (Mitchell, 1999).

The most developed approach is based on some sort of clustering methods. Clustering using the fuzzy $k$-means algorithm (fuzzy $c$-means) was described by Tou and Gonzalez (1974) and Fraisse et al. (1999). Yakushev et al. (2007) discussed a method for recognizing relatively homogeneous zones based on limit theorems of probability theory.

In recent years, some progress in the study of within-field variability has been achieved by application of a fuzzy indicator model (Kurtener et al., 2008; Torbert et al., 2009; Krueger et al., 2010). Using this model, it is possible to achieve agricultural field zoning on the bases of the combination of several soil and crop characteristics. This paper reports on the development of a fuzzy indicator model for definition of zones with different levels of productivity within an agricultural field. The theoretical considerations are illustrated with this example based on data collected from a precision agriculture study in central Texas, USA. 


\section{Method}

In the framework of fuzzy sets theory, it is possible to develop fuzzy indicator model, which would be useful to evaluate within-field variation of crop and soil data. In particular, fuzzy indicator model for identification of zones with different levels of productivity is based on two general types of fuzzy indicators: the individual fuzzy indicator (IFI) type and the combined fuzzy indicator (CFI) type. IFIs are defined as numbers in the range from 0 to 1 , which reflect an expert concept and are modeled by an appropriate membership function. CFI is defined by fuzzy aggregated operations. The basis of fuzzy indicator model and its applications are considered in several publications (Kurtener et al., 2008; Torbert et al., 2009; Krueger et al., 2010).

The structure of the fuzzy indicator model used in this study is shown in Figure 1. All individual fuzzy indicators (IFI) are built for each zone separately. In this study it is modeled by the trapezoidal-shaped built-in membership function because this function gives opportunity to model optimal area and to take into account the asymmetry of the transition zones.

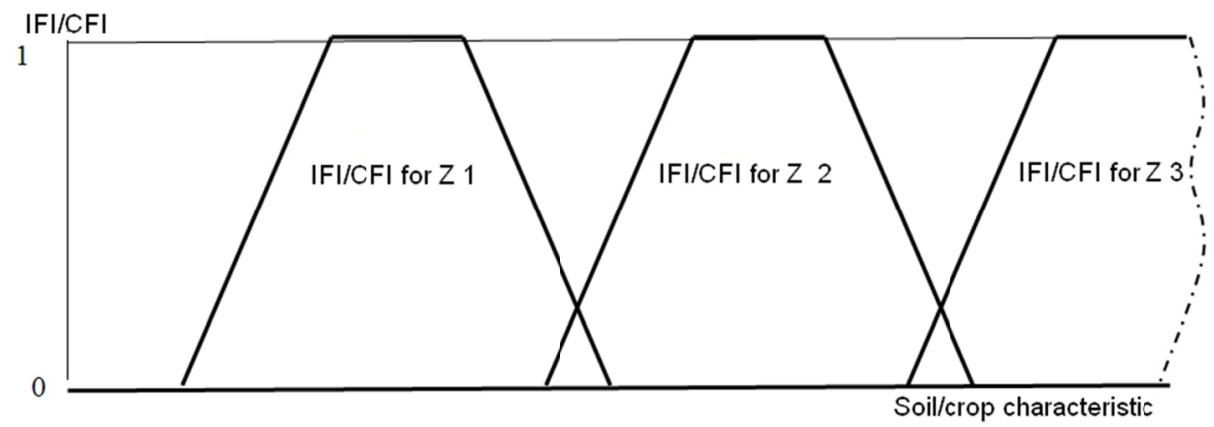

Figure 1. The structure of the fuzzy indicator model

In general, an algorithm for identification of zones with different levels of productivity includes four main parts: 1) Structuring Phase (perceiving the problem, input and output data, obtaining missed data using crisp models); 2) Fuzzy Modeling Phase (identifying fuzzy indicators, definition of membership functions, selecting fuzzy operations); 3) Programming Phase (selection of suitable existed software or designing a new one), and 4) Calculation and Visualization Phase (creation of thematic maps, interpretation of results obtained).

The calculations of fuzzy indicators were conducted utilizing the author's program, which included several scripts written on MATLAB 6.5 (http://www.mathworks.com/). For visualization, it could be applied to different GIS (Geographic Information System) software. In this study, we used the software product Sufer-8 (http://www.goldensoftware.com).

The fuzzy indicators model is an appropriate method for definition of zones with different levels of productivity within an agricultural field. Results of this model are illustrated with the following example.

\section{Results}

In this example, we used data from an experiment carried out on the north agricultural field located in Bell County, TX on the Elm Creek watershed (Torbert et al., 2000). The soils within the study site consisted of a Heiden clay (fine, montmorillonitic, thermic Udic Chromusterts), a Houston Black clay (fine, montmorillonitic, thermic Udic Pellusterts) and a Ferris clay (fine, montmorillonitic, thermic Udorthertic Chromusterts). Soil samples were collected at different points, taking into account the actual longitude and latitude for each of these points.

Preliminary analysis of the experimental data showed that the experimental field was relatively homogeneous. Nevertheless, we can distinguish two zones with medium productivity $(\mathrm{Z} 1)$ and good productivity $(\mathrm{Z} 2)$.

Because the experimental data contained information only about the parameters grain yield, total carbon $(C)$, total nitrogen $(\mathrm{N})$ and available phosphorus $(\mathrm{P})$, we were forced to restrict our calculations. The ranges of these parameters within the field and for each zone were made according to expert opinions and are give in Table 1. 
Table 1. The range of parameters

\begin{tabular}{lllll}
\hline & Total C, $\%$ & Total N, \% & Available P, \% & Yield, t/ha \\
\hline The range of parameters within the field & $1.95-3.04$ & $0.089-0.134$ & $0.027-0.043$ & $6.40-8.51$ \\
The range of parameters within Z 1 & $1.5-2.4$ & $0.05-0.1$ & $0.015-0.03$ & $6.28-7.53$ \\
The range of parameters within Z 2 & $2.41-3.5$ & $0.11-0.27$ & $0.031-0.045$ & $7.60-8.79$ \\
\hline
\end{tabular}

In this example, we used the trapezoidal-shaped built-in membership function. This function is characterized by four reference points: $x_{\text {lowl }}, x_{\text {optl }}, x_{\text {opt } 2}$, and $x_{\text {low2 } 2}$. Mathematically the trapezoidal-shaped built-in membership function is described as follows:

- $\quad$ If $x<x_{\text {lowl }}$, then IFI $=0$,

- If $x_{\text {lowl }}<x<\mathrm{x}_{\text {opt } 1}$, then $0<\mathrm{IFI}<1$,

- If $x_{\text {opt } 1}<x<\mathrm{x}_{\text {opt } 2}$, then IFI $=1$,

- If $x_{\text {opt } 2}<x<x_{\text {low } 2}$, then $1<$ IFI $<0$,

- If $x>x_{\text {low2 }}$, then IFI $=0$.

For example, reference points for the total carbon in areas with good productivity $(\mathrm{Z} 2)$ are: $x_{\text {lowl }}=2.3 \%, x_{\text {optl }}=$ $2.5 \%, x_{\text {opt } 2}=3.4 \%$, and $x_{\text {low } 2}=3.6 \%$.

Using the author's computer program, fuzzy indicators IFI/CFI were calculated for each zone separately. For illustration the results of calculations of fuzzy indicator on total carbon $\left(\mathrm{IFI}_{\mathrm{C}}\right)$ for both zones $\mathrm{Z} 1$ and $\mathrm{Z} 2$ are presented in Table 2.

Table 2. The results of the calculation of $\mathrm{IFI}_{\mathrm{C}}$

\begin{tabular}{|c|c|c|c|c|}
\hline \multirow[t]{2}{*}{ Longitude } & \multirow[t]{2}{*}{ Latitude } & \multirow{2}{*}{$\begin{array}{l}\text { Total C } \\
\%\end{array}$} & \multicolumn{2}{|l|}{$\mathrm{IFI}_{\mathrm{C}}$} \\
\hline & & & $\mathrm{Z} 1$ & $\mathrm{Z} 2$ \\
\hline 97.265707 & 31.025029 & 2.7 & 0 & 1 \\
\hline-97.264706 & 31.024772 & 2.76 & 0 & 1 \\
\hline-97.263738 & 31.024488 & 2.51 & 0 & 1 \\
\hline-97.264099 & 31.023627 & 2.32 & 0.08 & 0.55 \\
\hline-97.265099 & 31.023911 & 2.55 & 0 & 1 \\
\hline-97.266069 & 31.024141 & 3.04 & 0 & 1 \\
\hline-97.26643 & 31.023307 & 1.95 & 1 & 0 \\
\hline-97.265461 & 31.023023 & 2.32 & 0.08 & 0.55 \\
\hline-97.26676 & 31.022418 & 2 & 1 & 0 \\
\hline-97.267151 & 31.021638 & 2.04 & 0.98 & 0 \\
\hline-97.266057 & 31.021326 & 2.81 & 0 & 1 \\
\hline-97.265791 & 31.022134 & 2.78 & 0 & 1 \\
\hline-97.264398 & 31.022711 & 2.16 & 0.68 & 0.15 \\
\hline-97.264791 & 31.021823 & 2.47 & 0 & 0.925 \\
\hline-97.265088 & 31.021043 & 2.51 & 0 & 1 \\
\hline-97.263429 & 31.022427 & 2.1 & 0.875 & 0 \\
\hline-97.263759 & 31.021566 & 2.32 & 0.08 & 0.55 \\
\hline-97.26415 & 31.020786 & 2.21 & 0.45125 & 0.275 \\
\hline-97.26279 & 31.021309 & 2.47 & 0 & 0.925 \\
\hline
\end{tabular}


Table 2 shows the calculated values of $\mathrm{IFI}_{\mathrm{C}}$ for zones $\mathrm{Z} 1$ and $\mathrm{Z} 2$ for the input data (longitude, latitude, total C). It should be noted that the suggested method postulates that for each point in an agricultural field, different levels of productivity exist, but in different levels or grades. The value of the grade is estimated with fuzzy indicators, which range from 0 to 1 . For example, at the point in the agricultural field with longitude $=-97.265461$ and latitude $=31.023023$ (see row 4 in Table 2 ) there are two zones with different levels of productivity $(Z 1$ and $Z 2)$ where the grade was calculated to be 0.08 for zone $Z 1$ and 0.55 for zone $Z 2$. Because the value for $Z 2$ ( 0.55$)$ in much greater than $Z 1(0.08)$, then this point falls within zone $Z 2$. If any point, in which fuzzy indicators is equal to 0.5 (for zone $Z 1$ ) and 0.5 (for zone $Z 2$ ), then the state of this point will be uncertain.

Utilizing results of calculations we can build maps of zones with different levels of productivity. For illustration some results of visualization are shown in Figure 2 through Figure 5.

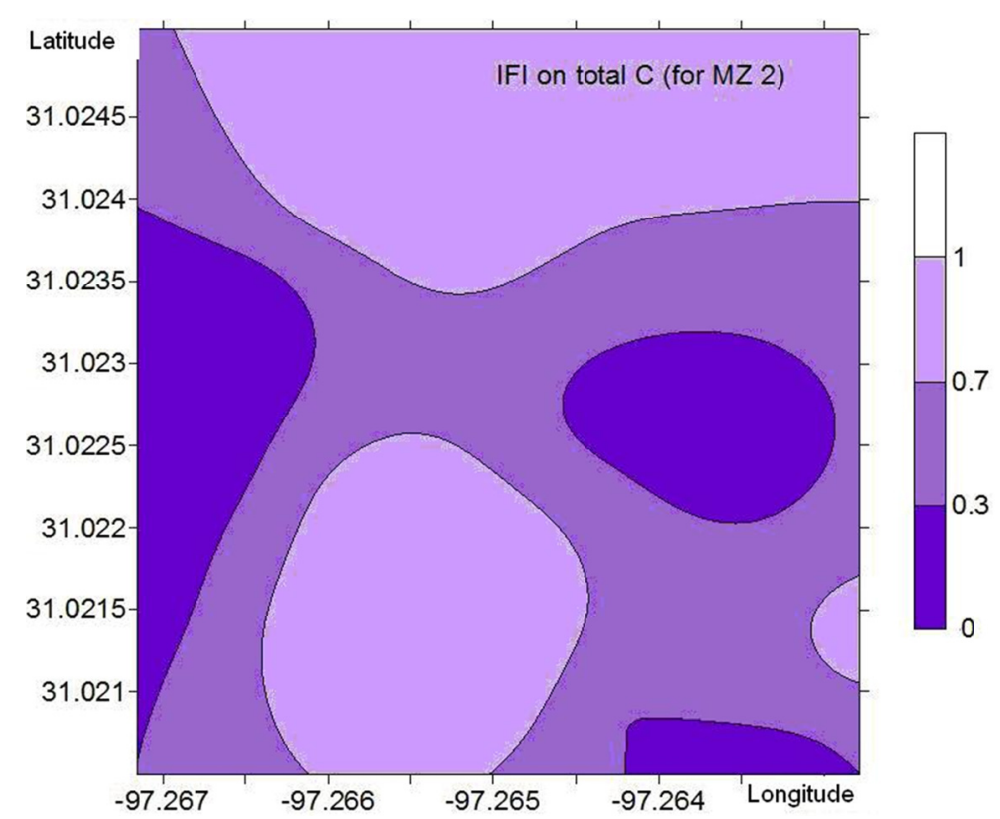

Figure 2. Zone with a good level of productivity defined on the basis of values of fuzzy indicator $\mathrm{IFI}_{\mathrm{C}}$

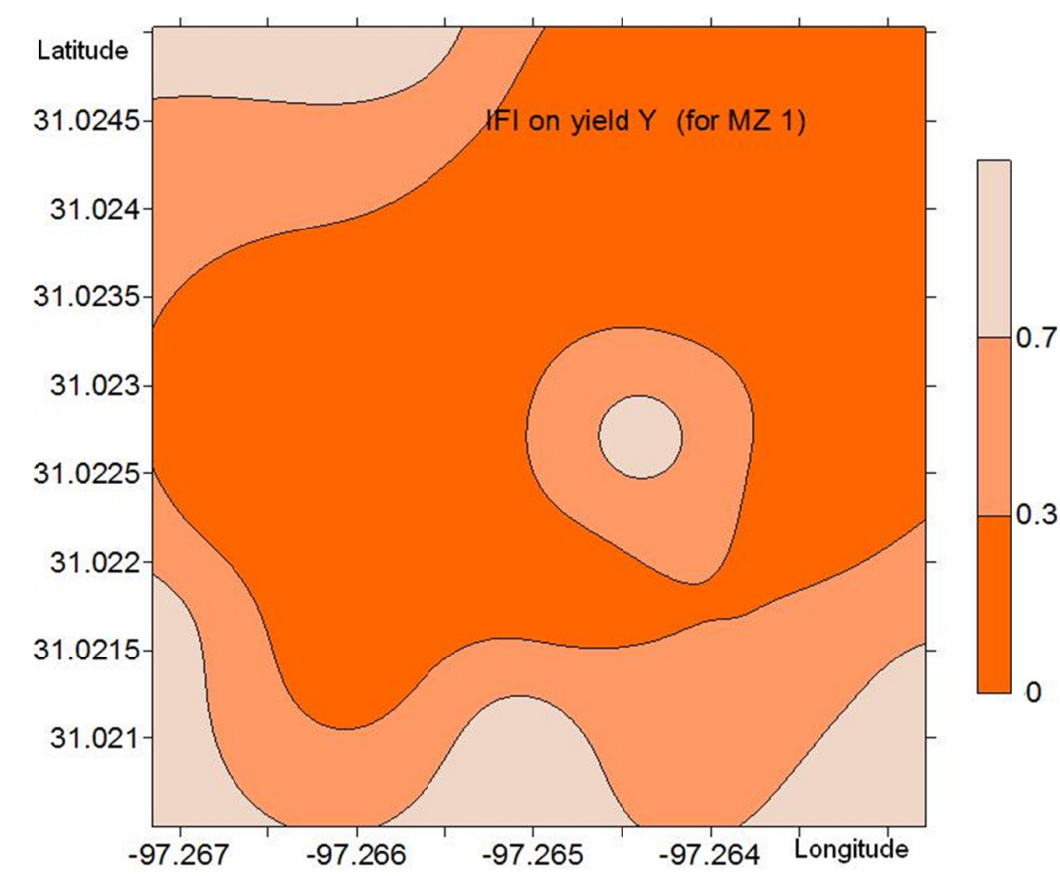

Figure 3. Zone with a medium level of productivity defined on the basis of values of fuzzy indicator $\mathrm{IFI}_{Y}$ 


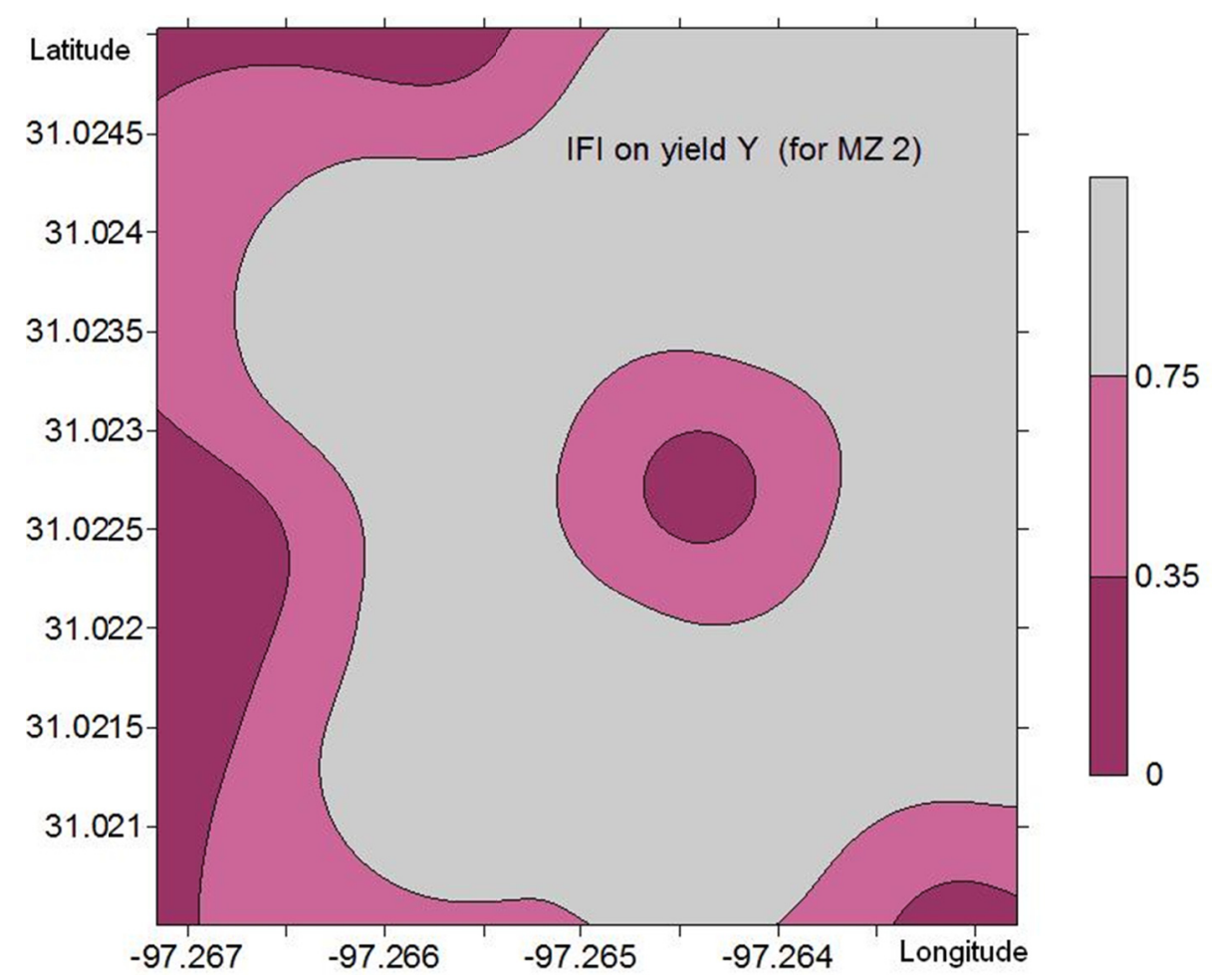

Figure 4. Zone with a good level of productivity defined on the basis of values of fuzzy indicator $\mathrm{IFI}_{\mathrm{Y}}$

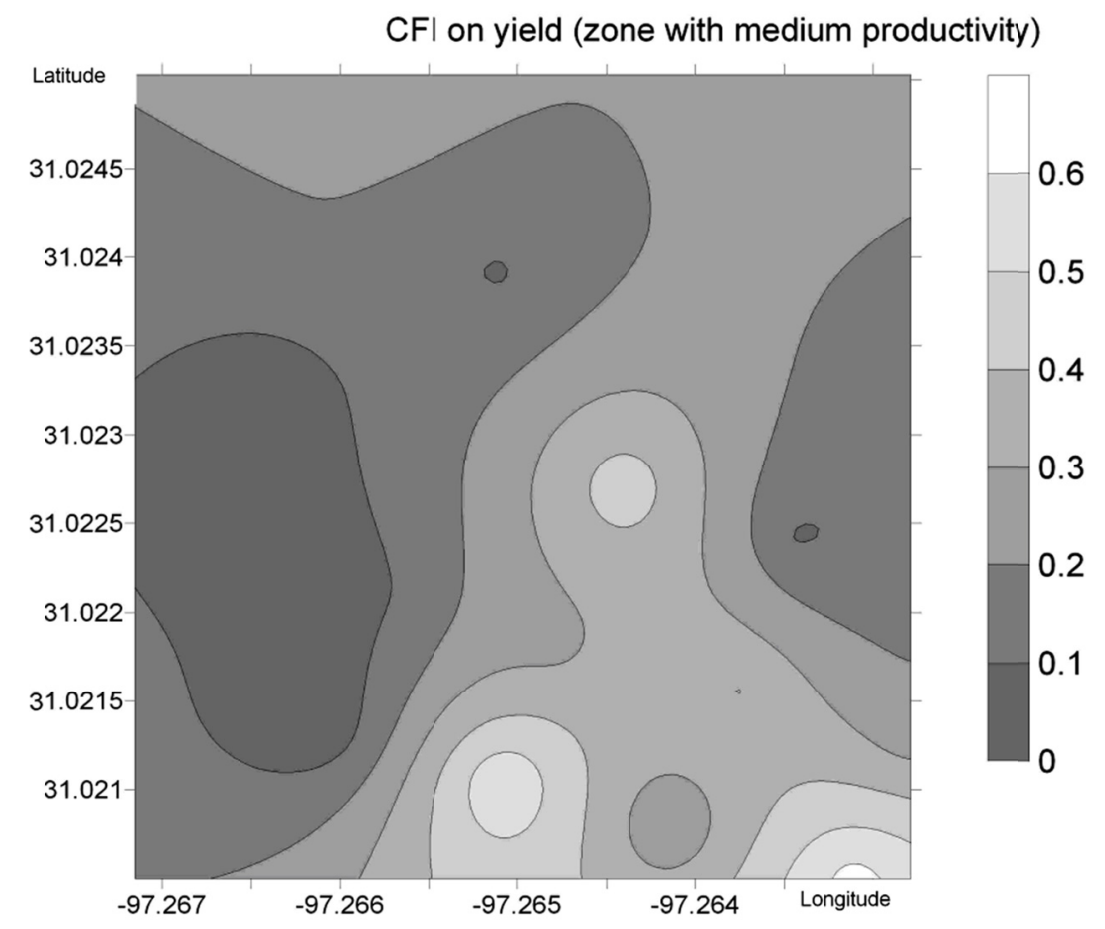

Figure 5. Zone with a medium level of productivity defined on the basis of values of fuzzy indicator CFI

In these figures, the zoning maps for the agricultural field can be observed within which the zones have different significance, which change from 0 to 1 . Generally, each map can be divided into 3 areas: a) an area zone with a strong level where the actual range is IFI/CFI $>0.5 ; b$ ) an area zone within which the presence of the zone is medium, with a range of $0.2<\mathrm{IFI} / \mathrm{CFI}<0.5$; and c) an area zone with a weak response, with a range of $0<$ $\mathrm{IFI} / \mathrm{CFI}<0.2$ (which practically does not exist). 
For example in Figure 5, the map based on values of fuzzy indicator CFI for zone with a medium level of productivity contains only the area within which the presence of the zone is medium $(0.2<\mathrm{CFI}<0.5)$ and the area within which the zone is weak $(0<\mathrm{CFI}<0.2)$ practically does not exist.

\section{Conclusion}

The backbone of this research is the development of an appropriate method for definition of zones with different levels of productivity within an agricultural field. This method is based on fuzzy indicator model, which could be very useful for analysis of within-field variability. To illustrate the proposed method, a series of calculations were made. As input data we used data from an experiment, conducted on the North agricultural field located in Bell County, TX on the Elm Creek watershed (Torbert et al., 2000).

\section{References}

Fraisse, C., Sudduth, K., Kitchen, N., \& Fridgen, J. (1999). Use of unsupervised clustering algorithms for delineating within-field management zones. Paper 993043.

Fridgen, J. J. (2000). Development and evaluation of unsupervised clustering software for sub-field delineation of agricultural fields. M.S. thesis. Univ. of Missouri, Columbia.

Fridgen, J., Kitchen, N., Sudduth, K., Drummond, S., Wiebold, W., \& Fraisse, C. (2004). Management Zone Analyst (MZA): software for subfield management zone delineation. Agronomy Journal, 96, 100-108. http://dx.doi.org/10.2134/agronj2004.0100

Handbook of precision agriculture - principles and applications. (2006). In Ancha Srinivasan (Ed.), Food Product Press, New York.

Krueger, E. D., Kurtener, D. A., \& Torbert, H. A. (2010). Evaluation of yield maps using fuzzy indicators. In The 10th Precision Agriculture International Conference Proceedings, July 18-21st, 2010, Denver, CO, USA.

Kurtener, Dmitry, Torbert, Allen, H., \& Krueger, E. (2008). Evaluation of agricultural land suitability: application of fuzzy indicators. In Lecture Notes in Computer Science 0302-9743 (Volume 5072/2008, pp. 475-490). Springer Berlin / Heidelberg.

Mitchell, A. (1999). Geographic Patterns and Relationships. The ESRI Guide to GIS Analysis, 1. NY, USA: Environmental Systems Research Institute Inc, ESRI Press.

Pilesjo, P., Thylen, L., \& Persson, A. (2000). Digital Elevation Models for Delineation of Agricultural Management Zones. In Second International Conference on Geo-spatial Information in Agriculture and Forestry, 10-12 January 2000, Florida, USA.

Stafford, J. V., Lark, R. M., \& Bolam, H. C. (1999). Using yield maps to recognize fields into potential management units. In Proceedings of the Fourth International Conference on Precision Agriculture, Madison, USA: American Society of Agronomy.

Torbert, H. A., Searcy, S. W., Kenimer, A. L., \& Roades, J. (2000). Precision farming effects on corn productivity and water quality. In Proc. $2^{\text {nd }}$ International Conference on Geospatial Information in Agriculture and Forestry. Lake Buena Vista, FL, USA.

Torbert, H. A., Yakushev, V., Krueger, E., \& Kurtener, D. (2009). Evaluation of Resources of Agricultural Lands Using Fuzzy Indicators. International Soil Tillage Research Organization Proceedings. 2009.

Tou, J. T., \& Gonzales, R. C. (1974). Pattern Recognition Principles (pp. 86-106). Addison-Wesley Publishing Company.

Yakushev, V. P., Bure, V. M., \& Yakushev, V. V. (2007). Identification of homogeneous zones on a field based on yield of individual plots. Russian Agric. Sci., 33, 176-179. http://dx.doi.org/10.3103/S1068367407030123 